\title{
Bucket feeding and teat feeding of acidified or non acidified milk feed for rearing dairy goats
}

\author{
Gystein HAVREVOLL
}

Agricultural University of Norway

Department of Animal Nutrition

Postbox 25, N-1432 AAS-NLH

Seven experiments were conducted in 402 female kids during the period 1982-1984. Teat feeding and bucket feeding were compared. Furthermore a trial was made to improve automatic teat feeding using fermented milk replacer and different weaning methods. Acidified skim milk was also tested in 5 to 10 week old kids.

Kids were removed from their dam at the age of 1-2 days and fed goat milk for 3-5 days. Then they were gradually changed to milk replacer $(200 \mathrm{~g}$ powder per 1 water $)$. Milk replacer contained 45 p. 100 skim milk powder and 35 p. 100 whey powder. Dry matter content was 96 p. 100 , crude protein was 20 p. 100 and crude fat was 19 p. 100.

Kids were weaned during the sixth week of life by restricted feeding with two meals a day. They had free access to water and hay. Concentrate was fed ad libitum up to a daily consumption of $0.4 \mathrm{~kg}$ per kid.

Bucket fed kids got 0.4-0.5 1 milk replacer per meal in two meals a day. Teat fed kids were allowed to suck milk replacer ad libitum before weaning. Over the three trials (224 kids), the pre-weaning weight gains were on an average $122 \mathrm{~g}$ per day for bucket fed kids versus $145 \mathrm{~g}$ per day for teat fed ones (significant difference $P \leqslant 5 \mathrm{p}$. 100). Post weaning weight gains were 131 and $128 \mathrm{~g}$ per day for bucket and teat fed animals, respectively. Bucket fed kids ingested $6.2 \mathrm{~kg}$ milk replacer each while automatically fed kids ingested about 50 p. 100 more. Moreover teat feeding saved labour compared to bucket feeding.

\section{Fermented milk replacer}

A commercial calf milk replacer (similar composition as for bucket/teat-feeding trials) was fermented by adding about 2 p. 100 starter culture and stored for $1-2$ days at $20^{\circ} \mathrm{C}$. The starter culture was fermented commercial skim milk with Streptococcus lactis, S. cremoris, S. diacetilactis and Leuconostoc citrovorum.

Acidified and non acidified milk replacer were fed ad libitum during 1-5 weeks of age from teat feeders. Kids got colostrum during the first week and they were weaned during the 6th week by feeding 0.75-1.0 1 per kid in one meal a day.

Pre-weaning weight gains were $139 \mathrm{~g} / \mathrm{day}$ on an average for 22 female kids fed non acidified milk replacer, versus $147 \mathrm{~g} / \mathrm{day}$ for $22 \mathrm{kids}$ fed fermented milk replacer (no significant difference, $P \leqslant 5$ p. 100).

Fermented milk replacer was stable when stored at ambient temperature. Kids fed sour milk replacer consumed $6.4 \mathrm{~kg}$ milk substitute and $0.4 \mathrm{~kg}$ less milk replacer compared to kids of the non-acidified group. Less refusals of milk feed and diarrhoea were observed in kids fed acidified milk replacer. Fifteen out of 44 kids were treated against diarrhoea during the 8 first weeks of life. Only 4 of them were fed sour milk replacer.

\section{Weaning methods}

Compared to restricted bucket feeding, ad libitum teat feeding of milk/milk replacer led to lower weight gains during and after weaning. In order to study different methods of weaning, fourty kids were randomly assigned to three groups at 25 days of age. All kids were fed cold fermented milk replacer (200 $\mathrm{g}$ powder per 1 water) ad libitum from teat feeders, until five weeks of age. They were weaned during the sixth week :

Group A got 3/4 1 per kid in one meal a day from teat feeders. Group B got concentrated milk replacer ad libitum (250 g powder per 1 for three days and $400 \mathrm{~g}$ powder per 1 for the next four days). Kids of group $\mathrm{C}$ had free access to cold fermented milk replacer 
from kidbar until weaning. Kids of both groups $B$ and $C$ were abruptly weaned at 6 weeks of age. The live weight of kids at 10 weeks of age was $12.1,13.1$ and $12.1 \mathrm{~kg}$ on an average in Groups $\mathrm{A}, \mathrm{B}$ and $\mathrm{C}$, respectively. Kid performances were satisfactory in all groups. However, abrupt weaned kids (Group C) exhibited a lower growth rate during the first 2-3 weeks post weaning.

In three trials with 107 kids the effect of feeding acidified skim milk from 5 to 10 weeks of age (group II) was compared to weaning with fermented milk replacer at 6 weeks of age (Group 1). Kids of group I were fed at a similar schedule as kids of group A above. Kids of Group II got 1-2 1 skim milk each per day from 5-10 weeks of age. All kids were weaned like those of Group A. Skim milk was acidified by adding 0.15 p. 100 acetic acid. Live weight at 10 weeks of age was 12.9 and $12.7 \mathrm{~kg}$ on an average in Group I and II, respectively. The skim milk fed kids suffered from diarrhoea. Thus feeding skim milk showed no beneficial effect on kid performance. Well growing kids can casily be weaned on dry feed at 6 weeks of age without any reduction in growth rate.

Key words : Teat feeding, kid, weaning, milk replacer, fermented milk.

\title{
The use of starch and soybean protein in intensive rearing of veal-type kids
}

\author{
Zafrira NITSAN, Y. CARASSO, I. NIR \\ Agricultural Research Organisation, The Volcani Center, Ministry of Agriculture, \\ The Hebrew University of Jerusalem, Faculty of Agriculture, Rehovot, Israel
}

The cost of milk replacers fed to suckling calves, lambs or kids, can be reduced by substituting part of the milk ingredients by feeds of plant origin. The present work was intended to determine the maximal amount of starch-soy mixture which is efficiently utilized by suckling kids when given in a liquid form. The effect of starch-soy mixture on the development of the gastrointestinal tract (GIT), the weight gain and the carcass fattening of kids was studied and compared to kids fed milk replacer or dry concentrate.

Twenty four Saanen male kids, about one week old, with an average weight of $4.6 \mathrm{~kg}$ were divided into 4 equal groups and kept in individual cages. The different groups received : 1) milk replacer $(M)$; 2) milk replacer + increasing amounts of heat treated corn starch-soy mixture (2:1) up to 30 p. 100 (TS) ; 3) as group 2 , but with raw corn starch up to 60 p. $100(\mathrm{~S}) ; 4)$ weaned at $38 \mathrm{~d}$ with free access to dry concentrate (C). The soystarch mixtures were combined with the milk replacer and fed together. In group 2 starchsoy mix was not increased above 30 p. 100 because at higher level food intake was depressed due to an excessive viscosity of the liquid replacer.

Kids were slaughtered when their weight attained or exceeded $18 \mathrm{~kg}$. The segments of the GIT were removed and weighed with and without their contents. The contents was stored at $-20^{\circ} \mathrm{C}$ for further analysis.

Feeding dry concentrate increased the weight of the 4 stomachs by $45 \mathrm{~kg} / \mathrm{kg}$ body weight in the dry concentrate fed kids vs about 18 in liquid dict fed ones. The weight of the intestine was not affected. Among the groups fed lipid diets, addition of starch-soy mixture sightly increased the weight of the rumen, reticulum and omasum and decreased the weight of the abomasum. The caecum of the $\mathrm{S}$ kids was significantly larger than in the other groups.

The pancreas weight was larger in the $S$ and $C$ kids than in $M$ and TS ones. The thickness of the small and large intestine estimated by the weight $(\mathrm{g}) / \mathrm{length}(\mathrm{m})$ ratio was largest in the $M$ group. 